\title{
Obstructive sleep apnoea
}

\author{
Sophie D. West ${ }^{1} \cdot$ Chris Turnbull ${ }^{2,3}$
}

Received: 26 October 2017 / Accepted: 14 November 2017 / Published online: 2 February 2018

(c) The Royal College of Ophthalmologists 2018

\begin{abstract}
Obstructive sleep apnoea (OSA) is increasing in prevalence due to rising obesity. While OSA is a disorder primarily of the upper airway during sleep, its pathophysiological impact on other body systems is increasingly recognised. There has been interest in the prevalence of OSA in different ophthalmic conditions and possible causation has been postulated. As OSA is common, it can be expected that people with co-existent OSA will be found in any ophthalmic disease population studied. To determine with confidence the significance of finding patients with OSA in a particular cohort requires a well matched control group, ideally matched for age, obesity, gender and co-morbidities. Only if one can say with certainty that the prevalence of OSA is higher in a group with a particular co-existent ophthalmic disease can we begin to speculate about possible mechanisms for the overlap in these conditions. Possible mechanisms for how OSA might affect the eye are discussed in this review. The current literature is reviewed with respect to diabetic retinopathy, glaucoma, floppy eyelid syndrome, non-arteritic ischaemic optic neuropathy, keratoconus and AMD. Associations with OSA have been found, but robust prospective studies using multi-channel sleep studies to diagnose OSA are lacking. Gaps remain in the evidence and in our knowledge. It is hoped that this review will highlight the need for ophthalmologists to consider OSA in their patients. It also makes recommendations for future research, especially to consider whether therapies for OSA can also be effective for ophthalmic disorders.
\end{abstract}

\section{What is obstructive sleep apnoea?}

Obstructive sleep apnoea (OSA) is a condition characterised by episodic upper airway narrowing during sleep. During sleep, the activity of the upper airway dilator muscles decreases in a sleep-stage-dependent manner [1]. This leads to narrowing of the upper airway, loud snoring, and reduction in airflow. Reduction in airflow can either be partial (a hypopnoea), or complete (an apnoea). The total number of apnoeas and hypopnoeas per hour of sleep is used to describe the severity of OSA: the apnoea hypopnoea index (AHI). OSA severity is arbitrarily defined based on thresholds: no OSA is an AHI $<5 / \mathrm{h}$, mild OSA AHI 5-15/

Sophie D. West

Sophie.west@nuth.nhs.uk

1 Newcastle Regional Sleep Service, Newcastle upon Tyne Hospitals NHS Trust, Newcastle, UK

2 Oxford Centre for Respiratory Medicine, Oxford University Hospitals, Oxford, UK

3 NIHR Biomedical Research Centre Oxford, University of Oxford, Churchill Campus, Oxford, UK h, moderate AHI 15-30/h and severe OSA AHI > 30/h [2]. The gold standard to assess OSA is polysomnography or multi-channel respiratory polygraphy ("sleep study"), although questionnaires to assess OSA risk are used both in the clinical setting to screen for OSA and to assess the prevalence of OSA in research populations.

OSA is common, although exact estimates of its prevalence depend on the severity of OSA, the presence/ absence of symptoms, and the exact population being studied [3, 4]. In 1993, Young et al published a communitybased study, where a population of 625 individuals between the age of 30 and 60 years, enriched for those with habitual snoring was studied [3]. An AHI of $\geq 5 / \mathrm{h}$ was found in $9 \%$ of women and $24 \%$ of men. OSA syndrome or OSAS, describes the presence of OSA on a sleep study plus daytime sleepiness. When OSA was defined as a combination of an $\mathrm{AHI} \geq 5 / \mathrm{h}$ plus excessive daytime sleepiness, the estimated prevalence was $2 \%$ of women and $4 \%$ of men. A more recent study estimated that approximately half of the middle-aged men and a quarter of the middle-aged women have moderate-to-severe sleep-disordered breathing on a sleep study, but estimates of OSAS were much lower [4].

The most recognised daytime consequence of OSA is daytime sleepiness [5]. OSAS also causes impaired quality 
of life [6], increases road traffic accidents [7, 8], and is associated with significant health care and economic burden [9].

\section{How is OSAS treated?}

Continuous positive airway pressure (CPAP) is the standard treatment for OSAS. CPAP is delivered via a portable bedside machine connected to a tight-fitting face mask (Fig. 1). CPAP works as a pneumatic splint, holding the upper airway open during sleep. CPAP is an effective therapy in improving patient symptoms in OSAS [5, 10]. CPAP also significantly improves quality of life indices [6]. Studies show improvements in sleepiness and quality of life even in those with minimally symptomatic or milder OSAS [11].

Other treatment options include weight loss, reducing alcohol and sedative medications, and mandibular advancement devices (MAD). Weight loss is an effective treatment for OSA [12]. Both dietary weight loss [13], and bariatric surgery [14], are effective in reducing the severity of OSA, although bariatric surgery leads to larger reductions in both weight and OSA severity. MAD reduce the severity of OSA and improve symptoms in patients with mild to moderate OSA [5].

\section{Screening tool for OSA: STOP-Bang}

Does the patient snore loudly (louder than talking or loud enough to be heard through closed doors)?

Does the patient often feel tired, fatigued, or sleepy during the day?

Has anyone observed the patient stop breathing during their sleep?

Does the patient have, or is the patient being treated for, high blood pressure?

Does the patient have a BMI of more than 35 ?

age. Is the patient older than 50 ?

Is the patient's neck circumference greater than $40 \mathrm{~cm}$ ?

Gender. Is the patient male? $\quad \mathrm{Y} / \mathrm{N}$

\section{Scoring: $Y \geq 3=$ high risk of $0 S A$ \\ $Y<3=$ low risk of $0 S A$}

Developed by Chung F, Yegneswaran B, Liao P, Chung SA, Vairavanathan S, Islam S, Khajehdehi A, Shapiro C. STOP Questionnaire A Tool to Screen Patients for Obstructive Sleep Apnea, 2008

Fig. 1 Screening tool to assess a patient for OSA, taken from obstructive sleep apnoea - a Guide for GPs, British Lung Foundation 2012
OSA is associated with increased cardiovascular disease $[15,16]$. In uncontrolled studies, patients who had severe OSA and who accepted CPAP had reduced cardiovascular events compared to those who did not use treatment, and similar levels of cardiovascular disease as control groups. However, randomised control trials have not shown similar improvements in cardiovascular disease with CPAP treatment $[17,18]$.

\section{How might OSA affect the eye?}

OSA has several acute physiological effects. Cessation of airflow during apnoeas leads to intermittent hypoxia, increased respiratory effort with large swings in intrathoracic pressure, arousal from sleep, sleep fragmentation, and sympathetic activation leading to blood pressure surges and heart rate rises. In turn, these lead to elevated daytime blood pressure, endothelial dysfunction, and potentially oxidative stress [19]. All of these mechanisms could potentially contribute to retinal vasculature damage and eye disease (Fig. 2).

\section{Hypertension, OSA and eye disease}

OSA is associated with increased blood pressure [20], and increased diagnoses of hypertension [21, 22]. Treating OSA with CPAP leads to small improvements of systolic and diastolic blood pressure of around $2-3 \mathrm{~mm} \mathrm{Hg}[23,24]$. The improvement in blood pressure with CPAP is increased in individuals with resistant hypertension [24].

Hypertension is a risk factor for numerous eye conditions, including those directly related to hypertension such as hypertensive retinopathy, choroidopathy and optic

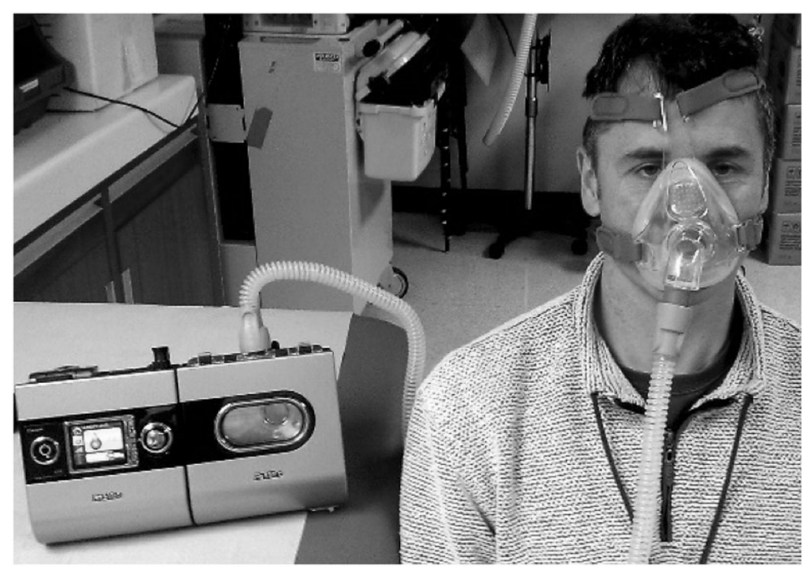

Fig. 2 Photograph showing continuous positive airway pressure (CPAP) therapy being used, with machine, humidifier, tubing and face mask (consent obtained) 
neuropathy [25], and other indirectly related diseases. Hypertension has been identified as a risk factor for diabetic retinopathy (DR) [26], and tighter blood pressure control reduced progression of retinopathy and reduced deterioration in visual acuity in the UKPDS study [27].

Associations between hypertension and age-related macular degeneration (AMD) have also been found. It is not clear whether hypertension is causal in AMD, perhaps by lowering choroidal blood flow, or whether hypertension and AMD simply share common pathological pathways such as oxidative stress and endothelial dysfunction [28].

The role of blood pressure in glaucoma is complex. Hypertension may be protective in younger adults, where it may increase ocular perfusion pressures and it may also be harmful when hypertensive changes are more established. With established hypertensive retinopathy, increases in arterial stiffness may lead to periods of reduced ocular perfusion pressure. In addition, hypotension or exaggerated blood pressure dips overnight may lead to low ocular perfusion pressures increasing glaucoma risk [29].

\section{Intermittent hypoxia, oxidative stress and inflammation}

Intermittent hypoxia is one of the main physiological consequences of OSA. It is likely to contribute to increased sympathetic activity, and therefore potentially elevated blood pressure [30]. Oxidative stress results from an imbalance between the production of reactive oxygen species and antioxidant mechanisms. Intermittent hypoxia potentially leads to oxidative stress by decreasing antioxidant mechanisms in periods of hypoxia and increasing reactive oxygen species production during periods of reoxygenation; termed an ischaemia-reperfusion injury [31].

Hypoxia, oxidative stress, and inflammation have been proposed as central mechanisms in the development of DR [32], AMD [33] and glaucoma [34].

Oxidative stress has been demonstrated in animals exposed to intermittent hypoxia [35-37]. However, oxidative stress has not been consistently found in OSA. Traditional blood and urine biomarkers of oxidative stress do not seem to be changed in OSA [38-40], but a novel breath analysis technique has identified a family of molecules that are linked to oxidative stress in patients with OSA during a brief withdrawal of their normal CPAP treatment [41]. Oxidative stress is probably tissue specific [42], and oxidative stress could be occurring in end-organ sites such as the retina without changes in urine or blood biomarkers. The retina may be particularly susceptible to oxidative stress due to risk factors such as high oxygen tensions and light exposure [34]. However, it is challenging to determine the relative importance of oxidative stress in both eye disease and OSA as current approaches have relied on blood and urine biomarkers that do not seem to reflect tissue specific oxidative stress.

\section{Endothelial dysfunction and vascular responses}

Endothelial function refers to the role of the endothelium in sensing and regulating blood flow. Flow-mediated dilatation at the brachial artery is a non-invasive method commonly used to assess endothelial function [43]. Endothelial dysfunction occurs in both hypertension [44], and in patients with coronary artery atherosclerosis [45]. It is thought to be an early stage in the development of cardiovascular disease. Endothelial dysfunction is also thought to play a role in DR.

Dynamic retinal vessel analysis (RVA) provides a mechanism by which retinal vessels can be assessed. RVA allows assessment of dynamic assessments of the calibre of retinal arterioles and venuoles. In addition, retinal vessel calibres can be assessed in response to a challenge such as a "flickering" light, which increases blood flow or to an increase in blood pressure during isometric exercise. The calibre of retinal arterioles and venuoles increase in healthy individuals during exposure to a "flickering" light [46]. This response is likely to represent endothelial function in the microvasculature, as it is, in part, blocked by nitric oxide inhibition [47]. "Flicker" responses are associated with flowmediated dilatation responses [48], which are the most common way of assessing endothelial function.

Endothelial function is impaired in patients with DR [49, 50], and in patients with coronary artery disease [51]. OSA has been shown to cause endothelial dysfunction in the brachial artery [52, 53], and similar changes in retinal vasculature response could explain the link between OSA and accelerated DR in OSA.

Other vascular responses are impaired in DR with paradoxical increases in retinal vessel diameter during isometric exercise [54]. Isometric exercise increases central blood pressure and decreases in retinal vessel size would normally be expected by autoregulation. OSA is associated with recurrent arousals overnight and these arousals are associated with sympathetic activity and large surges in blood pressure [55]. In patients with OSA and diabetes, a loss of autoregulation in the retinal vasculature could potentially leave the eye vulnerable to the large surges in blood pressure that occur overnight in OSA.

\section{OSA, type 2 diabetes and diabetic retinopathy}

Both OSA and type 2 diabetes mellitus (T2DM) are common, with obesity being the key mediator. While there is an 
Fig. 3 Potential mechanisms by which obstructive sleep apnoea causes retinal vasculature damage and eye disease

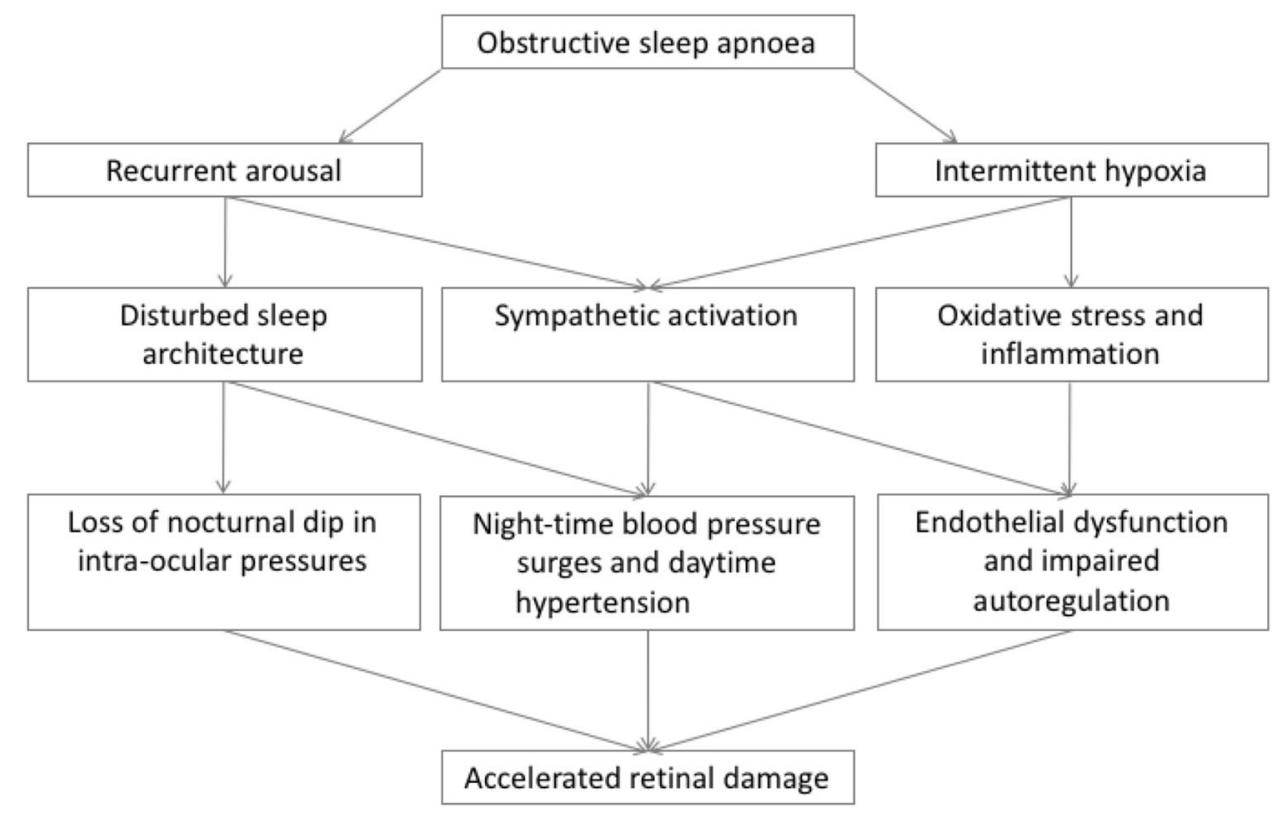

overlap between the two conditions, it is not entirely explained by obesity. In a UK prevalence study, 1682 men with T2DM, identified through primary and secondary care databases, were sent OSA screening questionnaires to determine their risk of OSA [56]. A subgroup of 240 respondents had home sleep studies. The results suggested that $23 \%$ of men with T2DM had moderate or severe OSA, which was significantly higher in this diabetes population than in a previous general population study of men with sleep studies $(p<0.001)$. Multiple linear regression revealed body mass index (BMI) and diabetes as significant independent predictors of OSA. Following correction for BMI (which explained $13 \%$ of the variance in OSA), diabetes itself explained a further $8 \%$ of the variance $(p<$ 0.001 ), raising questions about possible pharyngeal neuropathy or particular obesity distribution in T2DM predisposing to OSA.

In another prevalence study, in Chinese patients with T2DM in Hong Kong, 663 patients were randomly selected from the diabetes clinic and invited for polysomnography; the estimated OSA prevalence was $18 \%$ (25\% in men, $10 \%$ in women) [57]. Regression analysis identified that AHI was associated independently with higher BMI, advanced age, male sex, and higher diastolic blood pressure. A high prevalence of OSA was also observed in a sample of patients with T2DM invited to have sleep studies from four hospitals in Beijing [58]. In 210 patients, the prevalence of OSA was $67 \%$, with $20 \%$ having moderate-to-severe OSA. The lowest oxygen saturation was independently associated with proliferative DR and cerebral infarction.

From these three studies, it appears that a quarter of men with T2DM have significant OSA, and $10 \%$ of women.
OSA needs to be considered by clinicians seeing patients with T2DM, and any history of loud snoring, witnessed apnoeas, unrefreshing sleep and daytime sleepiness should prompt referral for sleep studies [59]. Figure 3 shows questions for screening patients for OSA ("Stop-Bang" questionnaire), to determine their risk when considering referral [60].

\section{Diabetic retinopathy (DR)}

It has been found that $10 \%$ of people with T2DM have evidence of DR at diagnosis [61]. UK National Institute for Health and Care Excellence (NICE) recommends referral for retinopathy screening within 3 months of diagnosis, and then every year [62].

OSA is common in people with DR. In 80 people with known diabetic clinically significant macular oedema (CSME) attending a UK Eye Hospital, 54\% were found to have moderate-to-severe OSA on sleep study screening, higher than expected from the matched control data [63]. Those with OSA were not sleepier, but they were older and more obese. No significant relationship was identified between the degree of macular thickness and the severity of OSA. In another UK-wide study, 718 people with diabetic macular oedema known to Eye Hospitals were offered screening for OSA with postal sleep studies. Of the 606 who completed sleep studies, $75 \%$ had evidence of OSA, $34 \%$ of whom had severe OSA [64]. These studies suggest that the prevalence of OSA is doubled in people with ophthalmic complications from T2DM, compared to those with T2DM alone. OSA should be considered by clinicians 
seeing these patients, with referral for sleep studies if indicated.

While several studies have shown that DR is worse in those patients with co-existing OSA, others have not shown this to be the case. The plausible hypothesis is that the intermittent hypoxia and blood pressure surges of OSA damage the retina. Using the same cohort of men with T2DMwho had sleep studies in their earlier prevalence study, West et al. looked at their most recent national retinal screening photography in 118 men [65]. In this cohort, 24\% had moderate or severe OSA on sleep study. Retinopathy and maculopathy scores were significantly worse in the OSA group, $p<0.0001$. While the OSA group had a significantly higher mean (SD) BMI than the non-OSA group 31.9 (5.2) versus $28.5(5.1) \mathrm{kg} / \mathrm{m}^{2}$ and larger neck size, the two groups did not differ significantly in terms of age, diabetes duration, diabetes treatment or HbA1c, smoking history or proportion with known hypertension. Multiple regression analysis showed only OSA and $\mathrm{HbAlc}$ to be significant independent predictors of retinopathy $\left(\mathrm{R}^{2}=\right.$ $0.19, p=<0.0001$ and $\mathrm{R}^{2}=0.04, p=0.03$ respectively). OSA was the only significant independent predictor of maculopathy $\left(R^{2}=0.3, p<0.001\right)$ and of the total microaneurysm score $\left(R^{2}=0.21, p=0.004\right)$.

In a smaller prospective study, 31 men with T2DM attending a hospital diabetes obesity clinic had sleep studies, exploratory blood tests and review of national screening photographs to obtain retinopathy and maculopathy grading [66]. The retinopathy score was significantly worse in the OSA group $(n=17, p=0.04)$, but not the maculopathy score. The proportion of patients with proliferative DR was significantly higher in the OSA group $(p=0.01)$. Multiple stepwise regression with adjustment for novel biomarkers showed only OSA to be a significant independent predictor of the total retinopathy score.

Kosseifi et al. performed a retrospective electronic chart review of 98 US veterans with well-controlled diabetes (HbAlc $<6.5 \%)$, referred for sleep studies over a 1-year period [67]. AHI was significantly related to diabetic microvascular complications, particularly retinopathy. Oxygen desaturation was significantly inversely related to microalbuminuria, microvascular complications, retinopathy, and $\mathrm{HbAlc}$. In another study, Change et al. retrospectively evaluated 317 people with DR and OSA, with review of polysomnography, coding and medical records [68]. After adjustment, an association was seen between DR and severe OSA (OR: 2.18, 95\% confidence CI: 1.14-4.18, $P=0.019)$. Proliferative DR was significantly associated with severe OSA (OR: 2.40 , 95\%CI: $1.12-5.14, p=0.024$ ). Diabetic macular oedema and severe OSA were also significantly associated (OR: 2.89, 95\%CI: 1.58-5.27, $P=$ $0.001)$.
Recently, a longitudinal study of 230 patients from diabetes clinics in two UK hospitals was conducted. OSA was assessed with sleep study and was present in $64 \%$ of people. Sight threatening DR (STDR) was present in $36 \%$; it was higher in patients with OSA compared to those without OSA (42.9 vs. $24.1 \%, p=0.004)$. After adjustment for confounders, OSA remained independently associated with STDR (OR: 2.3, 95\%CI: 1.1-4.9, $p=0.04$ ). After a median (IQR) follow-up of 43.0 (37.0-51.0) months, OSA patients were more likely to develop pre-/proliferative DR compared to non-OSA patients (18.4 vs. $6.1 \%, p=0.02)$. After adjustment for confounders, OSA remained an independent predictor of progression to pre-/proliferative DR (OR: 5.2, 95\%CI: $1.2-23.0, p=0.03$ ) [69].

While this data would appear to be compelling, there are other studies showing no association between OSA and retinopathy severity. Zhang explored the influence of OSA on diabetic complications in 880 hospitalised Chinese patients with T2DMacross 12 hospitals in China [70]. Potentially these were different, sicker patients than those out-patients of the other studies. Sixty percent of the cohort was found to have OSA on sleep recordings, $30 \%$ had DR and $4 \%$ had proliferative DR (PDR). There was no significant difference in the severity of OSA between those with and without DR or PDR in multivariate logistic regression, although the lowest oxygen saturation percentage in patients with PDR was lower than in those without PDR, $p=0.04$, in univariate analysis.

In Australia, a prospective observational study of 93 very obese patients was performed [71]. They divided the cohort into those with $(n=46)$ and without moderate or severe OSA $(n=47)$. The mean (SD) age: $52(10)$ years; BMI 47.3 (8.3) $\mathrm{kg} / \mathrm{m}^{2}$. Both groups were similar for ethnicity, BMI, cardiovascular co-morbidities, diabetes duration, HbA1c, and insulin treatment $(p>0.05)$. The moderate-to-severe OSA group was significantly more hypoxemic. There was no significant difference between groups for the presence of retinopathy (39 vs. 38\%). A greater proportion of moderateto-severe OSA patients had maculopathy ( 22 vs. $13 \%$ ), but this was not statistically significant. Logistic regression analyses showed AHI was not significantly associated with the presence of retinopathy or maculopathy $(p>0.05)$. While minimum oxygen saturation was not significantly associated with retinopathy, it was an independent predictor for the presence of maculopathy OR: 0.79 (95\%CI: $0.65-0.95 ; p<0.05$ ), after adjustment. These latter two studies raise questions about the pathophysiological mechanism of intermittent hypoxia in the development of retinal complications in patients with OSA.

More recently, Leong et al. performed a systematic review and meta-analysis of the effect of OSA on DR and maculopathy [72]. In the systematic review, they included 16 studies: one longitudinal, the rest cross-sectional, and all 
Fig. 4 Forest plot of the pooled estimate of the effects of minimum oxygen saturation on diabetic retinopathy using a random effects model; from a meta-analysis by Leong et al. [72]

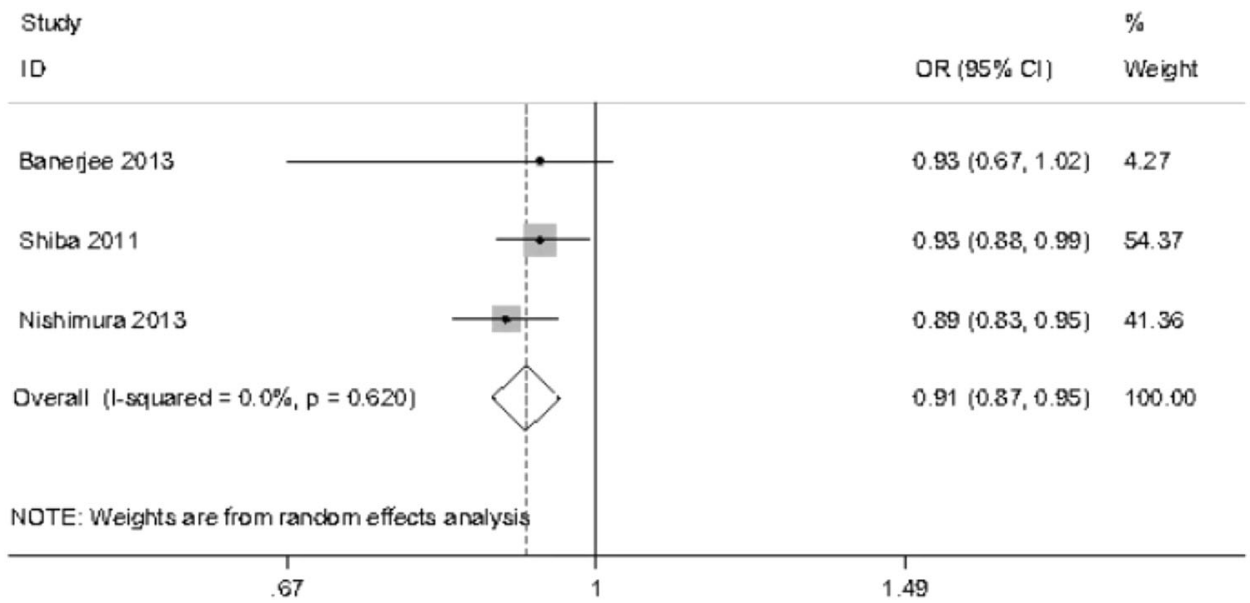

the studies listed above were included, except for the two which were published later $[68,70]$. Three studies were included in the meta-analysis. There were a total of 2731 participants, 2636 with type 2 diabetes. A range of diagnostic sleep tests were used, but OSA was diagnosed by sleep study rather than questionnaire in all studies. The definition of DR was noted to be variable. There was some evidence that OSA was associated with greater severity of DR as well as advanced DR in people with type 2 diabetes. The data on diabetic maculopathy were more limited and inconclusive. The level of hypoxaemia was again found to be associated with DR, but there were fewer studies reporting this variable (Fig. 4). The authors noted it was difficult to infer causality in cross-sectional studies and commented that further studies are needed.

There are much data exploring the associations between OSA and DR; the studies have been conducted across the world in different populations of people with T2DM - some recruited from diabetes clinics, some from in patient settings, some from Eye Hospitals. The studies differ between prospective observational studies and retrospective cohorts. Some patients were selected because they had well-controlled diabetes, while most did not take $\mathrm{HbA1c}$ into account for recruitment. They all used sleep studies to diagnose OSA, which adds to their strength. While some studies do show that DR is more significant in the presence of OSA, others do not and the differences in how the studies have been conducted and the populations they have been conducted in may account for these changes. The only study to assess longitudinal impact of OSA over many months to years suggested that OSA was an independent predictor of progression to pre- and proliferative DR [69]. While we do not fully understand the mechanisms for potentially worse DR in people with OSA, they are likely to reflect intermittent hypoxia, oxidative stress, catecholamine surges, blood pressure rises and endothelial dysfunction.

\section{CPAP and diabetic retinopathy}

In a review article from 2005, Sinclair and colleagues commented that to control DR, prompt detection was necessary, along with the management of "common systemic comorbid conditions such as hypertension, hyperlipidemia, anemia, obstructive sleep apnea, and smoking--all of which tend to accelerate its course and increase its severity" [73]. In their recent systematic review and metaanalysis, Leong et al. also concluded that the effect of CPAP on DR and diabetic macular oedema needed assessment through randomised controlled trials [72].

In a UK prospective cohort study, 35 people with diabetic macular oedema found to have moderate or severe OSA on screening sleep study were treated with CPAP, with a comprehensive assessment of visual function before and after 6 months of treatment [74], including logMAR visual acuity (VA), optical coherence tomography macular thickness, fundal photographs. They divided participants into high CPAP compliers $(n=13)$ and low CPAP compliers $(n=15)$ ( $\geq$ and $<2.5 \mathrm{~h} /$ night over the 6 months, respectively). At 6 months, the adjusted treatment effect on VA of high compliance versus low compliance was 0.11 (95\% CI: 0.21 to $-0.002 ; p=0.047$ ), equivalent to a oneline improvement on the $\log$ MAR chart. There was no significant improvement in macular oedema or fundal photographs. In another UK longitudinal study of 230 patients from diabetes clinics, it was observed that patients who received CPAP treatment were significantly less likely to develop pre-/proliferative DR, but they were not randomised to this treatment [69]. Neither study was randomised, and other factors are likely to influence who is prescribed and who adheres to CPAP, but both studies were hypothesis-generating and have led to interest in randomised controlled trials of CPAP. The ROSA trial (retinopathy and obstructive sleep apnoea) has recruited patients with diabetic macular oedema and newly diagnosed severe 
OSA from 23 Eye Hospitals across the UK and randomised them to 1 year of CPAP plus best ophthalmic care versus best ophthalmic care only [75]. Follow-up has completed in 2017 and results are pending.

\section{Bariatric surgery and diabetic retinopathy}

Amin et al. conducted a retrospective cohort study of the impact of bariatric surgery on retinopathy in patients with T2DM [76]. This represents an indirect method for treating OSA, via weight loss. They compared the national retinal screening photographs of 152 patients taken in the year before surgery to images taken a mean of $3.0 \pm 1.9$ years after surgery. The comparator group comprised patients with T2DM attending the same centre who had not undergone bariatric surgery. Compared with a group matched for age, $\mathrm{HbA}$ 1c and follow-up duration, only the progression to maculopathy was significantly less in patients who underwent surgery versus those who received routine care, 5.6\% $(8 / 143)$ versus $15.4 \%$ (16/104), $p=0.01$. Although OSA severity was likely to have decreased following bariatric surgery, they did not measure OSA, so its role in this relationship is unclear. Prospective randomised clinical trials are needed to ascertain the impact of bariatric surgery on retinopathy.

\section{OSA and type 1 diabetes}

Interactions between OSA and type 1 diabetes and ocular health are much less well studied. Manin et al. studied 67 consecutive people with Type 1 diabetes attending annual review with polysomnography [77]. The mean BMI of the cohort was $25.8 \pm 4.7 \mathrm{~kg} / \mathrm{m}^{2}$ and severe OSA $(A H I \geq 30 / h)$ was present in $19 \%$ of the patients, higher than would be expected in a control population, although this was not a case-control study. There were no significant differences in age, sex, BMI, HbA1c or Epworth sleepiness scale score between people with or without OSA. People with OSA had a longer course of diabetes ( $p$ $<0.01)$ and a higher prevalence of retinopathy $(p<0.01)$, neuropathy $(p=0.05)$, cardiovascular disease $(p<0.01)$ and hypertension $(p<0.01)$. The occurrence of macrovascular complications was independently associated with the presence of OSA (OR: 8.28; 95\% CI: 1.56-43.97; $P=$ 0.013 ) and the duration of diabetes (OR 1.08; 95\%CI, $1.02-1.15 ; \quad P=0.01)$. Retinopathy was independently associated with OSA (OR: 4.54; 95\% CI: 1.09-18.82; $P=$ $0.04)$ and the duration of diabetes (OR: $1.09 ; 95 \% \mathrm{CI}$ : 1.04-1.15; $P=0.001)$. This suggests similar potential mechanisms of OSA affecting the eye, whatever the nature of the diabetes.

\section{Glaucoma}

Previous studies of associations of OSA with glaucoma have shown variable results. A "vascular theory" suggests intermittent hypoxia affects the optic nerve, leading to optic neuropathy; a "mechanical theory" suggests OSA increases intraocular pressure (IOP) through changes in sleep architecture and increased sympathetic tone, with raised IOP causing optic nerve damage. Inflammation, oxidative stress and hypercapnia are also implicated. There have been many meta-analyses conducted in this area, which include large numbers, but no doubt each contains many of the same original studies, so the data are likely to be overlapping and the number of publications should not be confused necessarily with an increasing weight of evidence for this reason.

Six studies (three cohort study and three case-control studies), involving 2,288,701 participants were included in a meta-analysis by Liu et al. [78]. There was a significant association between OSA and glaucoma (adjusted-effect summary for case-control studies OR: 2.46; 95\% CI: 1.32-4.59, $P=0.005$. Adjusted-effect summary for cohort studies OR: 1.43 ; 95\%CI: $1.21-1.69, P=0.0001)$. Shi et al. sought to further evaluate the association between OSA and glaucoma with a meta-analysis of 16 studies with 2,278,832 individuals [79]. Glaucoma was diagnosed either by systematic eye examinations or by database or billing records, the latter two clearly being less robust. OSA was diagnosed mostly by polysomnography or overnight oximetry; one study used an unspecified questionnaire and some used database or billing records. Only four of the studies reported their results after adjusting for confounding factors. Using a fixed effects model, the pooled OR of six case-control studies was $1.96,95 \% \mathrm{CI}: 1.37-2.8, p=0.0002$. The metaanalysis of nine cross-sectional studies using a random effects model showed a pooled OR: 1.41, 95\% CI: $1.11-1.79, p=0.006$, but both results were based on unadjusted ORs. There is a suggestion therefore of an association of OSA with the prevalence of glaucoma, but the authors express concerns about possible confounders and highlight causation cannot be confirmed. They state OSA could be a marker of poor vascular health and obesity, not necessarily an independent risk factor for glaucoma.

Another meta-analysis of 12 international studies of 36,909 subjects found similar results, with OSA being associated with a significantly increased risk of glaucoma (OR: 1.65; 95\%CI: 1.44-1.88, $p<0.00001$ ) [80]. Asians and Caucasians had significantly increased glaucoma risk (OR: 1.78; 95\% CI: 1.49-2.12, $p<0.00001$ and 2.03; 95\% CI :1.12-3.69, $p=0.02$, respectively), along with women and men (OR: 1.81; 95\% CI: 1.27-2.57, $p=0.001$ and 1.62; 95\% CI: 1.29-2.03, $p<0.00001$, respectively). Estimates of glaucoma risk by OSA severity were highly varied, but only patients with severe OSA had a statistically 
significantly increased glaucoma risk (OR: $5.49 ; 95 \%$ CI: $1.04-33.83, p=0.04)$. A wider systematic review and meta-analysis was recently performed, of published observational studies on OSA to evaluate the association between OSA and ophthalmologic diseases [81]. The data was pooled for random-effects modelling. Relative to non-OSA subjects, OSA subjects had increased odds of diagnosis with glaucoma (pooled OR: $1.242 ; P<0.001$ ) and floppy eyelid syndrome (FES) (pooled OR: 4.157; $P<0.001$ ). In reverse, the overall pooled OR for OSA was $1.746(P=$ $0.002)$ in the glaucoma group, $3.126(P<0.0001)$ in the NAION group, and $2.019(P=0.028)$ in the central serous chorioretinopathy (CSR) group. For retinal vein occlusion, one study with 5965 OSA patients and 29,669 controls demonstrated a 1.94-fold odds increase in OSA patients. The authors suggest screening for OSA should be considered in patients with these diagnoses.

From these very large meta-analyses, we could conclude there seems to be an association of OSA with glaucoma. The three research studies listed below, however, have results that questions this association.

In the UK, a huge OSA cohort of 67,786 people was constructed from linked English hospital episode statistics over 12 years [82]. This cohort was compared to a reference cohort $(2,684,131$ people) for rates of subsequent Primary open-angle glaucoma (POAG) and age-related macular degeneration (AMD). A POAG cohort (comprising 87435 people) and an AMD cohort (248 408 people) were also constructed and compared with the reference cohort for rates of subsequent OSA. All analyses were restricted to people aged 55 and over and, within this age range, were age standardised using 5-year age groups. Risk of POAG following OSA was not elevated: the rate ratio for POAG was 1.01 (95\% CI: 0.85-1.19). Similarly, the risk of OSA following POAG was not elevated (OR 1.00, 95\% CI 0.86-1.17). These findings held true across subgroup analysis according to sex and age group. By contrast, the risk of AMD following sleep apnoea was significantly elevated (OR: 1.44, 95\%CI: 1.32-1.57).

In a French multicentre prospective cohort study, 9580 patients aged $>50$ years and suspected of having OSA were recruited from private practice, general and teaching hospitals [83]. Among these patients, 6754 had OSA and 330 had glaucoma. Glaucoma prevalence was $3.5 \%$ in patients with OSA and $3.1 \%$ in patients without OSA. OSA diagnosis did not significantly influence the risk of glaucoma in univariate analysis (OR: 1.13; 95\% CI: 0.87-1.47). The variables significantly influencing the odds of glaucoma with multivariate regression were age $>61.4$ years (OR: 1.55; 95\%CI: $1.23-1.95$ ), $\mathrm{BMI}<30 \mathrm{~kg} / \mathrm{m}^{2}$ (OR: $1.58 ; 95 \%$ CI: 1.26-1.99), female gender (OR: $1.40 ; 95 \%$ CI: 1.11-1.78), arterial hypertension (OR: $1.32 ; 95 \%$ CI: 1.05-1.67), high triglyceride levels (OR: 2.03; 95\%CI:
1.43-2.88) and thyroid dysfunction (OR: $1.52 ; 95 \% \mathrm{CI}$ : 1.09-2.11). This was a large, prospective, well-conducted study.

In a retrospective, matched-cohort study conducted in Taiwan, the data from the Longitudinal Health Insurance Database 2000 were studied [84]. There were 1012 subjects with OSA included in the study cohort and randomly selected 6072 subjects in the comparison group. Each subject was individually traced for a 5-year period to identify those subjects who subsequently received a diagnosis of OAG. During the 5-year follow-up period, the incidence rate per 1000 person-years was 11.26 (95\% CI: 8.61-14.49) and 6.76 (95\% CI: 5.80-7.83) for subjects with and without OSA, respectively. After adjusting for monthly income, geographic region, diabetes, hypertension, coronary heart disease, obesity, hyperlipidaemia, renal disease, hypothyroidism, and the number of outpatient visits for ophthalmologic care during the follow-up period, stratified Cox proportional hazards regression revealed that the hazard ratio for OAG within the 5-year period for subjects with OSA was 1.67 (95\% CI: $1.30-2.17 ; P<0.001$ ) that of comparison subjects, suggesting that OSA is associated with an increased risk of subsequent OAG diagnosis during a 5-year follow-up period.

It is difficult then to be clear about the association between OSA and glaucoma. More research is clearly needed.

\section{CPAP and glaucoma}

An early study sought to analyse the influence of CPAP on IOP [85]. Eighteen patients previously diagnosed as having glaucoma and 22 normal subjects were studied. Sleep studies were not performed, so it is not known whether they had OSA. CPAP was used during wakefulness, at +12 $\mathrm{cmH} 2 \mathrm{O}$ for $15 \mathrm{~min}$. The results showed that CPAP significantly increased IOP in patients with glaucoma (before CPAP (mean $+/$ - SEM) $20.3+/-6.3 \mathrm{~mm} \mathrm{Hg}$; after CPAP $22.3+/-5.7 \mathrm{~mm} \mathrm{Hg}$ ). The authors stated that "CPAP might be relatively contraindicated in difficult to manage glaucoma patients, if these results are corroborated". $15 \mathrm{~min}$ of CPAP during wakefulness in someone who has not used it before who may not have OSA cannot be compared to of the experience of using CPAP over a whole night during sleep for OSA. These small studies can be hypothesis generating, but in isolation cannot influence CPAP practice for OSA.

Kiekens et al. tried to answer this question more definitively. Twenty one patients with newly diagnosed OSA had serial measurements of IOP made before CPAP therapy, and again 1 month after the initiation of CPAP therapy [86]. One patient in this cohort had glaucoma. Baseline 
measurements showed significant diurnal fluctuation in average IOP, with highest IOPs at night. After 1 month of CPAP therapy, the average IOP was significantly higher than baseline. The increase in overnight IOP was also significantly higher. The mean difference between trough and peak IOP was $6.7+/-1.5 \mathrm{~mm} \mathrm{Hg}$ at baseline and $9.0+/-$ $2.0 \mathrm{~mm} \mathrm{Hg}$ during CPAP therapy. $30 \mathrm{~min}$ after CPAP cessation a significant decrease in IOP was recorded. There was a statistically significant decrease in mean OPP during CPAP therapy. The authors suggested that regular screening of visual fields and the optic disc is warranted for all patients with OSA, especially those treated with CPAP because of these changes in IOP.

Cohen et al. measured the IOP of newly diagnosed OSAS patients before and after CPAP treatment $(n=31)$ [87]. Only three patients had glaucoma. The IOP was measured in sitting and supine positions before, during, and after the sleep period. The mean IOP of the after CPAP and before CPAP groups measured in sitting position before the sleep period was $13.33 \pm 2.04 \mathrm{~mm} \mathrm{Hg}$ and 14.02 $\pm 2.44 \mathrm{~mm} \mathrm{Hg}$, respectively $(p=0.9)$. Assuming a supine position for 1 min significantly increased the IOP by 1.93 $\mathrm{mm} \mathrm{Hg}$ and $2.13 \mathrm{~mm} \mathrm{Hg}$ for both groups, but with no difference between the two groups. The IOP increased significantly further after $7 \mathrm{~h}$ of sleep in the supine position, and the mean IOP of the after and before CPAP groups was $19.2 \pm 5.68 \mathrm{~mm} \mathrm{Hg}$ and $19.69 \pm 5.61 \mathrm{~mm} \mathrm{Hg}$, respectively $(p=0.74)$. CPAP therapy did not affect the measured IOP.

Finally, Ulusoy et al. investigated the effect of using CPAP on glaucoma prevalence [88]. Consecutive patients with severe OSAS and 36 healthy controls with no OSA confirmed on polysomnography were studied with full ophthalmic examination. The OSA group was divided into 38 who used CPAP and 32 who did not. All three groups were similar in terms of BMI and neck circumference. The AHI was comparable in the CPAP and no CPAP groups (mean AHI $62.9 \pm 27.0$ vs. $55.6 \pm 27.3 / \mathrm{h}$ ). IOP was significantly higher in the no CPAP group $(16.7 \pm 3.1 \mathrm{~mm} \mathrm{Hg})$ than CPAP group $(15.1 \pm 3.5 \mathrm{~mm} \mathrm{Hg})$ or control group $(14.1 \pm 2.4), p<0.001$. Glaucoma prevalence was cited as $12.5 \%$ in the no CPAP group, $5.2 \%$ in the CPAP group and $0 \%$ in the control group. Although the study suggests CPAP does not increase IOP and may prevent development of glaucoma complications, this study's design limits the conclusions that can be reached. There is no description of where the patients and controls were recruited from, and no comment on comorbid and potentially confounding disease. The control population was not matched in any way. There were no baseline ocular measures before CPAP. Subjects were not randomised to CPAP, but selected whether or not to use it. This may have reflected their other health usage behaviours, with CPAP users perhaps being less likely to smoke, more likely to take other medicines, and so on. None of this data are available, or discussed.

In the area of how CPAP affects IOP in patients with glaucoma, we are still unclear and randomised controlled trials are required to determine definitively cause and effect. Currently patients commencing CPAP do not routinely have IOP measured or visual fields checked and the authors are not aware of any routine practice with respect to this in patients with glaucoma starting CPAP.

\section{Floppy eyelid syndrome (FES)}

Associations of FES with OSA have previously been shown, along with obesity, diabetes, hypertension and ischaemic heart disease. Anecdotally, FES patients in particular seem to be screened for OSA symptoms in the Eye Clinic and referred to the Sleep clinic; perhaps because there has been awareness of an association with OSA for longer [89]. In a later review, McNab comments that "FES patients have a very high incidence of OSA and a causal relationship may exist, but amongst patients with OSA, FES is uncommon but commoner than in the general population" [90].

In a case-control study, 102 patients with FES were compared to 102 patients recruited from a DR clinic and matched 1:1 on age, gender, BMI [91]. Patients were screened for OSA using the Epworth sleepiness score (ESS), but no estimate of risk of OSA was made with questionnaires and sleep studies were not performed. The authors describe significant associations between FES and OSA $(P=0.0008)$, keratoconus $(P<0.0001)$, lash ptosis $(P<0.0001)$, dermatochalasis $(P=0.02)$, upper lid medial canthal laxity $(P=0.02)$, upper lid distraction $(P=0.001)$, palpebral aperture $(P=0.004)$, and levator function $(P=$ $0.005)$, but, in fact, they are only significant associations with self-reported daytime sleepiness, measured by ESS. Once again this is a hypothesis-generating study that begs for further research with sleep studies.

Fowler et al. performed a case-based retrospective review of all patients seen at the University of North Carolina with a diagnosis of FES, which identified 14 patients involving 17 eyelids [92]. A literature review was also performed, yielding a total 324 cases. From the combined data $(n=$ 338 ), the overall minimum prevalence of OSA in patients with lax eyelid condition was $16 \%$ compared with an estimated 9-24\% in the general population. Of patients with FES, those identified with OSA had significantly more individuals with obesity (76 vs. 20\%) and male gender (89 vs. $61 \%$ ) than the group without OSA, which fits with known prevalence data [3]. The authors concluded OSA occurs no more commonly in obese men with FES than in obese men without FES, suggesting FES is an 
"epiphenomenon" only, but may predict OSA and should alert the clinician to ask further questions about sleep.

Muniesa et al. in Spain studied 114 patients who had been admitted for OSA evaluation and 45 patients with FES with sleep studies, eyelid laxity measurement and slit-lamp examination [93]. There was a significantly higher incidence of eyelid hyperlaxity in those diagnosed with OSA than in the non-OSA patients $(p=0.004)$. Thirty-eight of the 45 patients with FES were diagnosed with OSA (85\%) and $65 \%$ had severe OSA. In another study by the same group, 152 patients were included to investigate whether FES could be an indicator of glaucoma in patients with OSA [94]. There were 75 patients with OSA and without FES; 52 patients with OSA and FES; and 25 non-OSA patients. The prevalence of glaucoma in OSA patients without FES was 5\% (4/75). One patient had primary openangle glaucoma and 3 had previously diagnosed glaucoma. The prevalence of glaucoma in OSA patients with FES was $23 \%(12 / 52)(p=0.004)$. None of the 25 patients without OSA had glaucoma. When adjustments were made for age and BMI, this significance remained $(P=0.04)$, suggesting FES may be a useful way to identify individuals with a greater probability of having glaucoma in the OSA population.

Fox et al. in the USA performed a cross-sectional observational study of 201 people referred for overnight sleep studies [95]. Their mean (SD) age was 53.2 (13.5) years and $43 \%(n=87)$ were female. They assessed eyelid laxity and ocular surface disease on bedside ophthalmologic examination. After adjustment, no association was observed between OSA severity and an eyelid laxity score (regression coefficient, $0.85 ; 95 \% \mathrm{CI},-0.33$ to $0.62 ; P=0.4)$ or an ocular surface score (regression coefficient, $1.09 ; 95 \% \mathrm{CI}$ : -0.32 to $0.29 ; P=.93$ ). Through subset analysis, male sex was associated with a higher ocular surface score, while older age and diabetes were associated with a higher eyelid laxity score. Only one patient $(0.5 \%)$ exhibited findings of FES.

Bayir sought to evaluate a surgical treatment for OSA, anterior palatoplasty, on FES patients with OSA [96]. Sixtytwo sleep clinic patients found to have mild or moderate OSA on sleep study were recruited and screened for FES. Patients could choose whether they had surgical treatment for OSA $(n=35)$ and if they did not opt for this, they formed the control group $(n=27)$. They were therefore not randomised, although the two groups appear to be well matched. Ophthalmic examinations were performed before polysomnography to look for FES, and these examinations were repeated 3 months later following palatal surgery. Polysomnography was repeated in the surgical group but not in the control group. Surgical success was defined as a fall in AHI of $50 \%$ or greater. At baseline, $60 \%$ of patients in the surgical group were diagnosed with FES and $56 \%$ in the control group. This percentage fell to $26 \%$ in the surgical group post-operatively. Surgery is said to have been successful in $57 \%$ of patients; the proportion of people with FES fell from 60 to $10 \%, p=0.02$. The authors postulate that the correction of tissue hypoxia may be responsible for the improvement in FES. Again, patients were not randomised to their treatment arm, which introduces a selection bias. There are no comments on weight loss in either group, which would profoundly affect the severity of OSA. The success rate of the surgery on AHI seems very high and not in keeping with other literature on surgical therapies in OSA, which are generally not recommended as a single treatment [97]. Also there is no repeat 3 month polysomnogram in the control group, who may have lost weight or changed sleeping position after OSA diagnosis (having opted not to have palatal surgery) or whose sleep indices may have shown regression to the mean and improved. The improvements in FES seem impressive, but the initial prevalence is high and the total numbers of patients are small; the authors conclude larger studies are warranted.

\section{Nonarteritic anterior ischaemic optic neuropathy (NAION)}

NAION is an acute optic neuropathy for which a multifactorial cause is postulated, with associations with vascular dysfunction, crowded optic nerve, hypertension, hypercholesterolaemia and diabetes. OSA is also considered a potential risk factor, not least because many people discover this visual defect on waking. There are fewer studies, presumably because it is a more unusual condition.

Aptel published a cohort study looking at 89 patients diagnosed with NAION, who underwent polysomnography; 85 were followed for 3 years [98]. Of the cohort, $75 \%$ had OSA at diagnosis; they were more likely to develop NAION in their other eye $(15.4$ vs. $9.5 \%, 95 \% \mathrm{CI} 0.2 \%$ to $11.5 \%, p$ $=0.04$ ). Patients with severe OSA who were non-adherent with CPAP therapy were at increased risk of developing involvement in the second eye when compared with those with no OSA or moderate OSA not requiring CPAP (HR: 5.54, 95\% CI: 1.13-27.11, $p=0.04)$. The authors acknowledged that the group who are non-adherent with CPAP could be biased towards being non-compliant with other therapies.

$\mathrm{Wu}$ et al. performed a systematic review and metaanalysis to investigate the association between OSA and NAION [99]. They identified four prospective cohort studies and one case-control study. The studies ranged in size from 17 to 73 in each group. OSA was diagnosed by sleep studies in four studies and Sleep Disorders Questionnaire in 
one. The pooled OR of developing NAION in subjects with OSA was 6.18, 95\% CI: 2-19.11 versus non-OSA controls, $p=0.002$. Potential confounders were not adjusted for in all the studies, which may have affected the results.

\section{Keratoconus}

The role of hypoxia and reperfusion injury has been questioned in the development of keratoconus, hence the role of OSA in possible causation has been questioned.

Gencer et al. from Turkey performed a prospective, casecontrolled multicentre study on 146 keratoconus patients and 146 age- and gender-matched control subjects [100]. They used the Berlin Questionnaire to attribute high or low risk of OSA, but found no difference in risk of OSA between the two groups. In contrast, in a prevalence study in USA, 362 patients diagnosed with keratoconus over a 14year period were identified [101]. Then 101 completed questionnaires including the Berlin questionnaire for OSA. The prevalence of previously diagnosed OSA was $18 \%$. Of the remaining patients $(n=83), 47 \%$ were high risk for OSA.

The Berlin questionnaire used in both of these studies to determine risk of OSA was not validated with sleep studies. While the Berlin questionnaire was reported to have a sensitivity of $86 \%$ and specificity of $77 \%$ for OSA diagnosis, others have not obtained such results [102, 56]. The different populations studied here may account for the variation in results, and further studies with case-control populations and sleep studies are warranted.

In a large prospective case-control study, 616 patients diagnosed with keratoconus were enroled, along with 616 age, gender and BMI matched controls attending the cornea clinic for refractive errors [103]. Patients had telephone interviews including the Berlin questionnaire. The mean BMI of the keratoconus group $24.4 \mathrm{~kg} / \mathrm{m}^{2}$, mean age 25.3 years. The keratoconus group had a significantly higher history of previously diagnosed OSA, 2.9 vs. $0.6 \%, p=$ 0.004 and were at higher risk of OSA, 12.3 vs. $6.5 \%, p=$ 0.001 . Those patients at high risk of OSA had more severe keratoconus than those at low risk of OSA, $p<0.05$. Unsurprisingly, higher BMI was an independent risk factor for increased risk of OSA in patients with keratoconus in multivariate logistic regression, as was family history of OSA. In the control group, surprisingly only female gender was associated with a higher Berlin score defined risk of OSA. The number of patients with high risk of sleep apnoea in the control arm were relatively low $(n=40)$, OSA was not confirmed by sleep studies and in other prevalence studies, male gender has been found to be a risk factor for OSA [3].

\section{Age-related macular degeneration (AMD)}

Anti-vascular endothelial growth factor injections (VEGF) are a common treatment for the exudative subtype of AMD, although non-response to therapy is common. Some postulate OSA may contribute to this non-response.

In the USA, a case-control study was performed to investigate OSA risk in patients with exudative AMD or diabetic macular oedema with poor response to anti-VEGF therapy with bevacizumab [104]. Both groups were compared with age-matched controls. 103 patients with AMD were recruited; 56 (54\%) had nonexudative AMD and 47 (46\%) had exudative AMD, of which 14 (30\%) had poor response exudative $\mathrm{AMD}$ and were at a significantly higher risk of OSA based on questionnaires $(p<0.05)$. Of 30 diabetic macular oedema patients with cystoid macular oedema, $19 \%$ received 1 injection, $82 \%$ received 2 or more consecutive injections, and $73 \%$ received 3 or more consecutive injections. Risk for OSA increased significantly with increasing number of injections $(p<0.05)$. In common with all the other studies discussed, cause and effect cannot be proven, but the importance of asking about OSA symptoms is highlighted.

In a small study from Israel, all patients recruited had exudative AMD and received treatment with intravitreal bevacizumab [105]. All patients also had OSA and were categorised into 2 groups: 18 untreated and 20 treated with CPAP. These were not randomly assigned groups. The treated OSA group received $8 \pm 7$ total injections; the untreated OSA group received $16 \pm 4$ injections $(P<0.05)$. The treated OSA group achieved statistically significant better visual acuity (logMAR, $0.3 \pm 0.24,20 / 40)$, as opposed to the untreated group (logMAR, $0.7 \pm 0.41 ; P<$ 0.05). Central retinal thickness improved in the treated OSA group compared with the untreated group: $358 \pm 95$ to 254 $\pm 45 \mu \mathrm{m}$ and $350 \pm 75$ to $322 \pm 105 \mu \mathrm{m}$, respectively $(P<$ 0.05, 20/100). Again, those who do not use CPAP may differ from CPAP users in other ways, which may affect their response to bevacizumab. It is hypothesis generating and raises questions about identifying and treating OSA earlier in patients with exudative AMD to potentially yield better functional outcomes.

\section{Future directions for research into OSA and the eye}

The literature shows much interest in eye disorders and OSA. The physiological consequences of OSA could plausibly lead to eye disease. However, prospective studies are lacking, acknowledged by all the authors of the retrospective studies and meta-analyses reviewed here; thus only 
limited conclusions can be drawn about associations between eye disorders and OSA. There are so far no published randomised controlled trials of treatment with CPAP in this field; these have been found to be a robust method of establishing cause and effect of OSA on associated disease. There are suggestions of associations between OSA and glaucoma, keratoconus, NAION and severity of DR. Causality is not established and there are many common confounders for ocular disorders and OSA. Certainly, given the prevalence of OSA, it is important for ophthalmologists to be aware of its symptoms and wonder about its pathophysiological potential to impact in the patients with eye disease they are treating. We have recently led a UK ophthalmology research network and would encourage members of this network or other teams to design robust studies based on the hypotheses developed by some of the studies listed here, to increase the evidence base for the links between OSA and the eye.

Funding support and sponsorship: CT was supported/funded by the NIHR Oxford Biomedical Research Centre.

\section{Compliance with ethical standards}

Conflict of interest SDW and CT received consultancy fees from Bayer.

\section{References}

1. Carberry JC, Jordan AS, White DP, Wellman A, Eckert DJ. Upper airway collapsibility (Pcrit) and pharyngeal dilator muscle activity are sleep stage dependent. Sleep. 2016;39:511-21.

2. Berry RB, Budhiraja R, Gottlieb DJ, Gozal D, Iber C, Kapur VK, et al. Rules for scoring respiratory events in sleep: update of the 2007 AASM Manual for the Scoring of Sleep and Associated Events. Deliberations of the Sleep Apnea Definitions Task Force of the American Academy of Sleep Medicine. J Clin Sleep Med. 2012;8:597-619.

3. Young T, Palta M, Dempsey J, Skatrud J, Weber S, Badr S. The occurrence of sleep-disordered breathing among middle-aged adults. N Engl J Med. 1993;328:1230-5.

4. Heinzer R, Vat S, Marques-Vidal P, Marti-Soler H, Andries D, Tobback N, et al. Prevalence of sleep-disordered breathing in the general population: the HypnoLaus study. Lancet Respir Med. 2015;3:310-8.

5. Sharples LD, Clutterbuck-James AL, Glover MJ, Bennett MS, Chadwick R, Pittman MA, et al. Meta-analysis of randomised controlled trials of oral mandibular advancement devices and continuous positive airway pressure for obstructive sleep apnoeahypopnoea. Sleep Med Rev. 2016;27:108-24.

6. Jenkinson C, Davies RJ, Mullins R, Stradling JR. Comparison of therapeutic and subtherapeutic nasal continuous positive airway pressure for obstructive sleep apnoea: a randomised prospective parallel trial. Lancet. 1999;353:2100-5.

7. Barbé F, Pericás J, Muñoz A, Findley L, Antó JM, Agustí AG. Automobile accidents in patients with sleep apnea syndrome. An epidemiological and mechanistic study. Am J Respir Crit Care Med. 1998;158:18-22.
8. Tregear S, Reston J, Schoelles K, Phillips B, Obstructive sleep apnea and risk of motor vehicle crash: systematic review and meta-analysis. J Clin Sleep Med. 2009;5:573-81.

9. Sjösten N, Kivimäki M, Oksanen T, Salo P, Saaresranta T, Virtanen M, et al. Obstructive sleep apnoea syndrome as a predictor of work disability. Respir Med. 2009;103:1047-55.

10. Gupta MA, Simpson FC, Lyons DCA. The effect of treating obstructive sleep apnea with positive airway pressure on depression and other subjective symptoms: A systematic review and meta-analysis. Sleep Med Rev. 2016;28:55-68.

11. Craig SE, Kohler M, Nicoll D, Bratton DJ, Nunn A, Davies R, et al. Continuous positive airway pressure improves sleepiness but not calculated vascular risk in patients with minimally symptomatic obstructive sleep apnoea: the MOSAIC randomised controlled trial. Thorax. 2012;67:1090-6.

12. Schwartz AR, Gold AR, Schubert N, Stryzak A, Wise RA, Permutt $S$, et al. Effect of weight loss on upper airway collapsibility in obstructive sleep apnea. Am Rev Respir Dis. 1991;144:494-8.

13. Iftikhar IH, Bittencourt L, Youngstedt SD, Ayas N, Cistulli P, Schwab R, et al. Comparative efficacy of CPAP, MADs, exercise-training, and dietary weight loss for sleep apnea: a network meta-analysis. Sleep Med. 2017;30:7-14.

14. Greenburg DL, Lettieri CJ, Eliasson AH. Effects of surgical weight loss on measures of obstructive sleep apnea: a metaanalysis. Am J Med. 2009;122:535-42.

15. Marin JM, Carrizo SJ, Vicente E, Agusti AGN. Long-term cardiovascular outcomes in men with obstructive sleep apnoeahypopnoea with or without treatment with continuous positive airway pressure: an observational study. Lancet . 2005;365:1046-53.

16. Young T, Finn L, Peppard PE, Szklo-Coxe M, Austin D, Nieto FJ, et al. Sleep disordered breathing and mortality: eighteen-year follow-up of the Wisconsin sleep cohort. Sleep. 2008;31:1071-8.

17. McEvoy RD, Antic NA, Heeley E, Luo Y, Ou Q, Zhang X, et al. CPAP for prevention of cardiovascular events in obstructive sleep apnea. N Engl J Med. 2016;375:919-31.

18. Peker Y, Glantz H, Eulenburg C, Wegscheider K, Herlitz J, Thunström E. Effect of positive airway pressure on cardiovascular outcomes in coronary artery disease patients with nonsleepy obstructive sleep apnea. The RICCADSA Randomized Controlled Trial. Am J Respir Crit Care Med. 2016;194:613-20.

19. Kohler M, Stradling JR. Mechanisms of vascular damage in obstructive sleep apnea. Nat Rev Cardiol. 2010;7:677-85.

20. Davies CW, Crosby JH, Mullins RL, Barbour C, Davies RJ, Stradling JR. Case-control study of $24 \mathrm{~h}$ ambulatory blood pressure in patients with obstructive sleep apnoea and normal matched control subjects. Thorax. 2000;55:736-40.

21. Peppard PE, Young T, Palta M, Skatrud J. Prospective study of the association between sleep-disordered breathing and hypertension. N Engl J Med. 2000;342:1378-84.

22. Nieto FJ, Young TB, Lind BK, Shahar E, Samet JM, Redline S, et al. Association of sleep-disordered breathing, sleep apnea, and hypertension in a large community-based study. Sleep Heart Health Study. JAMA. 2000;283:1829-36.

23. Pepperell JCT, Ramdassingh-Dow S, Crosthwaite N, Mullins R, Jenkinson C, Stradling JR, et al. Ambulatory blood pressure after therapeutic and subtherapeutic nasal continuous positive airway pressure for obstructive sleep apnoea: a randomised parallel trial. Lancet. 2002;359:204-10.

24. Hu X, Fan J, Chen S, Yin Y, Zrenner B. The role of continuous positive airway pressure in blood pressure control for patients with obstructive sleep apnea and hypertension: a meta-analysis of randomized controlled trials. J Clin Hypertens (Greenwich). $2015 ; 17: 215-22$. 
25. Konstantinidis L, Guex-Crosier Y. Hypertension and the eye. Curr Opin Ophthalmol. 2016;27:514-21.

26. Do DV, Wang X, Vedula SS, Marrone M, Sleilati G, Hawkins BS, et al. Blood pressure control for diabetic retinopathy. Cochrane Database Syst Rev. 2015;1:CD006127.

27. Tight blood pressure control and risk of macrovascular and microvascular complications in type 2 diabetes: UKPDS 38. UK Prospective Diabetes Study Group. BMJ. 1998;317:703-13.

28. Katsi VK, Marketou ME, Vrachatis DA, Manolis AJ, Nihoyannopoulos $\mathrm{P}$, Tousoulis $\mathrm{D}$, et al. Essential hypertension in the pathogenesis of age-related macular degeneration: a review of the current evidence. J Hypertens. 2015;33:2382-8.

29. Choi J, Kook MS. Systemic and ocular hemodynamic risk factors in glaucoma. BioMed Res Int. 2015;2015:141905.

30. Tamisier R, Pépin JL, Rémy J, Baguet JP, Taylor JA, Weiss JW, et al. 14 nights of intermittent hypoxia elevate daytime blood pressure and sympathetic activity in healthy humans. Eur Respir J. 2011;37:119-28.

31. Neri M, Riezzo I, Pascale N, Pomara C, Turillazzi E. Ischemia/ reperfusion injury following acute myocardial infarction: a critical issue for clinicians and forensic pathologists. Mediat Inflamm. 2017;2017:7018393.

32. Arden GB, Sivaprasad S. Hypoxia and oxidative stress in the causation of diabetic retinopathy. Curr Diabetes Rev. 2011;7:291-304.

33. Blasiak J, Petrovski G, Veréb Z, Facskó A, Kaarniranta K. Oxidative stress, hypoxia, and autophagy in the neovascular processes of age-related macular degeneration. BioMed Res Int. 2014;2014:768026.

34. Chrysostomou V, Rezania F, Trounce IA, Crowston JG. Oxidative stress and mitochondrial dysfunction in glaucoma. Curr Opin Pharmacol. 2013;13:12-5.

35. Chen L, Einbinder E, Zhang Q, Hasday J, Balke CW, Scharf SM. Oxidative stress and left ventricular function with chronic intermittent hypoxia in rats. Am J Respir Crit Care Med. 2005;172:915-20.

36. Row BW, Liu R, Xu W, Kheirandish L, Gozal D. Intermittent hypoxia is associated with oxidative stress and spatial learning deficits in the rat. Am J Respir Crit Care Med. 2003; 167:1548-53.

37. Troncoso Brindeiro CM, da Silva AQ, Allahdadi KJ, Youngblood V, Kanagy NL. Reactive oxygen species contribute to sleep apnea-induced hypertension in rats. Am J Physiol Heart Circ Physiol. 2007;293:H2971-2976.

38. Paz Y, Mar HL, Hazen SL, Tracy RP, Strohl KP, Auckley D, Bena $J$, et al. Effect of continuous positive airway pressure on cardiovascular biomarkers: the sleep apnea stress randomized controlled trial. Chest. 2016;150:80-90.

39. Stradling JR, Schwarz EI, Schlatzer C, Manuel AR, Lee R, Antoniades $\mathrm{C}$, et al. Biomarkers of oxidative stress following continuous positive airway pressure withdrawal: data from two randomised trials. Eur Respir J. 2015;46:1065-71.

40. Turnbull CD, Akoumianakis I, Antoniades C, Stradling JR. Overnight urinary isoprostanes as a marker of oxidative stress in obstructive sleep apnoea. Eur Respir J. 2017;49. 49(2) pii: 1601787

41. Schwarz EI, Martinez-Lozano Sinues P, Bregy L, Gaisl T, Garcia Gomez D, Gaugg MT, et al. Effects of CPAP therapy withdrawal on exhaled breath pattern in obstructive sleep apnoea. Thorax. 2016;71:110-7.

42. Margaritis M, Sanna F, Lazaros G, Akoumianakis I, Patel S, Antonopoulos AS et al. Predictive value of telomere length on outcome following acute myocardial infarction: evidence for contrasting effects of vascular vs. blood oxidative stress. Eur Heart J. 2017;38:3094-104.
43. Celermajer DS, Sorensen KE, Gooch VM, Spiegelhalter DJ, Miller OI, Sullivan ID, et al. Non-invasive detection of endothelial dysfunction in children and adults at risk of atherosclerosis. Lancet Lond Engl. 1992;340:1111-5.

44. Antony I, Lerebours G, Nitenberg A. Loss of flow-dependent coronary artery dilatation in patients with hypertension. Circulation . 1995;91:1624-8.

45. Cox DA, Vita JA, Treasure CB, Fish RD, Alexander RW, Ganz P, et al. Atherosclerosis impairs flow-mediated dilation of coronary arteries in humans. Circulation. 1989;80:458-65.

46. Dorner GT, Garhöfer G, Huemer KH, Riva CE, Wolzt M, Schmetterer L. Hyperglycemia affects flicker-induced vasodilation in the retina of healthy subjects. Vision Res. 2003;43:1495-500.

47. Dorner GT, Garhofer G, Kiss B, Polska E, Polak K, Riva CE, et al. Nitric oxide regulates retinal vascular tone in humans. Am J Physiol Heart Circ Physiol. 2003;285:H631-6.

48. Pemp B, Weigert G, Karl K, Petzl U, Wolzt M, Schmetterer L, et al. Correlation of flicker-induced and flow-mediated vasodilatation in patients with endothelial dysfunction and healthy volunteers. Diabetes Care. 2009;32:1536-41.

49. Mandecka A, Dawczynski J, Blum M, Müller N, Kloos C, Wolf $\mathrm{G}$, et al. Influence of flickering light on the retinal vessels in diabetic patients. Diabetes Care. 2007;30:3048-52.

50. Nguyen TT, Kawasaki R, Wang JJ, Kreis AJ, Shaw J, Vilser W, et al. Flicker light-induced retinal vasodilation in diabetes and diabetic retinopathy. Diabetes Care. 2009;32:2075-80.

51. Heitmar R, Cubbidge RP, Lip GYH, Gherghel D, Blann AD. Altered blood vessel responses in the eye and finger in coronary artery disease. Invest Ophthalmol Vis Sci. 2011;52:6199-205.

52. Kohler M, Stoewhas A-C, Ayers L, Senn O, Bloch KE, Russi EW, et al. Effects of continuous positive airway pressure therapy withdrawal in patients with obstructive sleep apnea: a randomized controlled trial. Am J Respir Crit Care Med. 2011;184:1192-9.

53. Schwarz EI, Puhan MA, Schlatzer C, Stradling JR, Kohler M. Effect of CPAP therapy on endothelial function in obstructive sleep apnoea: A systematic review and meta-analysis. Respirol Carlton Vic. 2015;20:889-95.

54. Frederiksen CA, Jeppesen P, Knudsen ST, Poulsen PL, Mogensen CE, Bek T. The blood pressure-induced diameter response of retinal arterioles decreases with increasing diabetic maculopathy. Graefes Arch Clin Exp Ophthalmol. 2006;244:1255-61.

55. Ali NJ, Davies RJ, Fleetham JA, Stradling JR. The acute effects of continuous positive airway pressure and oxygen administration on blood pressure during obstructive sleep apnea. Chest. 1992;101:1526-32.

56. West SD, Nicoll DJ, Stradling JR. Prevalence of obstructive sleep apnoea in men with type 2 diabetes. Thorax. 2006;61:945-50.

57. Lam DC, Lui MM, Lam JC, Ong LH, Lam KS, Ip MS. Prevalence and recognition of obstructive sleep apnea in Chinese patients with type 2 diabetes mellitus. Chest. 2010;138:1101-7.

58. Zhang R, Guo X, Guo L, Lu J, Zhou X, Ji L. Prevalence and associated factors of obstructive sleep apnea in hospitalized patients with type 2 diabetes in Beijing, China 2. J Diabetes. 2015;7:16-23.

59. Shaw JE, Punjabi NM, Wilding JP, Alberti KG, Zimmet PZ. International Diabetes Federation Taskforce on epidemiology and prevention. sleep-disordered breathing and type 2 diabetes: a report from the international diabetes federation taskforce on epidemiology and prevention. Diabetes Res Clin Pract. 2008;81:2-12. 
60. Chung F, Yegneswaran B, Liao P, Chung SA, Vairavanathan S, Islam S, et al. STOP questionnaire: a tool to screen patients for obstructive sleep apnea. Anesthesiology. 2008;108:812-21.

61. Ruta LM, Magliano DJ, Lemesurier R, Taylor HR, Zimmet PZ, Shaw JE. Prevalence of diabetic retinopathy in Type 2 diabetes in developing and developed countries. DiabetMed. 2013;30:387-98.

62. Internal Clinical Guidelines Team. Type 2 diabetes in adults: management. NICE Guideline [NG28]. London: National Institute for Health and Care Excellence (UK); 2017.

63. Mason RH, West SD, Kiire CA, Groves DC, Lipinski HJ, Jaycock A, et al. High prevalence of sleep disordered breathing in patients with diabetic macular edema. Retina. 2012;32:1791-8.

64. Prudon B, Hughes J, West S. A novel postal-based approach to diagnosing obstructive sleep apnoea in a high-risk population. Sleep Med. 2017;33:1-5.

65. West SD, Groves DC, Lipinski HJ, Nicoll DJ, Mason RH, Scanlon PH, et al. The prevalence of retinopathy in men with Type 2 diabetes and obstructive sleep apnoea. Diabet Med. 2010;27:423-30.

66. Rudrappa S, Warren G, Idris I. Obstructive sleep apnoea is associated with the development and progression of diabetic retinopathy, independent of conventional risk factors and novel biomarkers for diabetic retinopathy. $\mathrm{Br} \mathrm{J}$ Ophthalmol. 2012;96:1535.

67. Kosseifi S, Bailey B, Price R, Roy TM, Byrd RP Jr, Peiris AN. The association between obstructive sleep apnea syndrome and microvascular complications in well-controlled diabetic patients. Mil Med. 2010;175:913-6.

68. Chang AC, Fox TP, Wang S, Wu AY. Relationship between Obstructive Sleep Apnea and the presence and severity of diabetic retinopathy. Retina. 2017. https://doi.org/10.1097/IAE. 0000000000001848.

69. Altaf QA, Dodson P, Ali A, Raymond NT, Wharton H, Fellows $\mathrm{H}$ et al. Obstructive sleep apnoea and retinopathy in patients with type 2 diabetes: a longitudinal study. Am J Respir Crit Care Med. 2017. https://doi.org/10.1164/rccm.201701-0175OC..

70. Zhang R, Zhang P, Zhao F, Han X, Ji L. Association of diabetic microvascular complications and parameters of obstructive sleep apnea in patients with type 2 diabetes. Diabetes Technol Ther. 2016;18:415-20.

71. Banerjee D, Leong WB, Arora T, Nolen M, Punamiya V, Grunstein R, et al. The potential association between obstructive sleep apnea and diabetic retinopathy in severe obesity-the role of hypoxemia. PLoS ONE. 2013;8:e79521.

72. Leong WB, Jadhakhan F, Tahei S, Chen YF, Adab P, Thomas GN. Effect of obstructive sleep apnoea on diabetic retinopathy and maculopathy: a systematic review and meta-analysis. Diabet Med. 2016;33:158-68.

73. Sinclair SH, Malamut R, Delvecchio C, Li W. Diabetic retinopathy: treating systemic conditions aggressively can save sight. Cleve Clin J Med. 2005;72:447-54

74. Mason RH, Kiire CA, Groves DC, Lipinski HJ, Jaycock A, Winter BC, et al. Visual improvement following continuous positive airway pressure therapy in diabetic subjects with clinically significant macular oedema and obstructive sleep apnoea: proof of principle study. Respiration. 2012;84:275-82.

75. West SD, Hughes J, Prudon B. Baseline data from the ROSA trial: a randomised controlled trial of the effect of CPAP on diabetic macular oedema in people with concurrent Obstructive Sleep Apnoea. ATS. 2016:P1071.

76. Amin AM, Wharton H, Clarke M, Syed A, Dodson P, Tahrani AA. The impact of bariatric surgery on retinopathy in patients with type 2 diabetes: a retrospective cohort study. Surg Obes Relat Dis. 2016;12:606-12.
77. Manin G, Pons A, Baltzinger P, Moreau F, Iamandi C, Wilhelm JM, et al. Obstructive sleep apnoea in people with Type 1 diabetes: prevalence and association with micro- and macrovascular complications. Diabet Med. 2015;32:90-6.

78. Liu S, Lin Y, Liu X. Meta-analysis of association of obstructive sleep apnea with glaucoma. J Glaucoma. 2016;25:1-7.

79. Shi Y, Liu P, Guan J, Lu Y, Su K. Association between glaucoma and obstructive sleep apnea syndrome: a meta-analysis and systematic review. PLoS ONE. 2015;10:e0115625.

80. Wu X, Liu H. Obstructive sleep apnea/hypopnea syndrome increases glaucoma risk: evidence from a meta-analysis. Int $\mathrm{J}$ Clin Exp Med. 2015;8:297-303.

81. Huon LK, Liu SY, Camacho M, Guilleminault C. The association between ophthalmologic diseases and obstructive sleep apnea: a systematic review and meta-analysis. Sleep Breath. 2016;20:1145-54.

82. Keenan TD, Goldacre R, Goldacre MJ, Associations between obstructive sleep apnoea, primary open-angle glaucoma and agerelated macular degeneration: record linkage study. Br J Ophthalmol. 2017;101:155-9.

83. Aptel F, Chiquet C, Tamisier R, Sapene M, Martin F, Stach B, et al. Association between glaucoma and sleep apnea in a large French multicenter prospective cohort. Sleep Med. 2014;15:576-81.

84. Lin $\mathrm{CC}, \mathrm{Hu} \mathrm{CC}$, Ho JD, Chiu HW, Lin HC. Obstructive sleep apnea and increased risk of glaucoma: a populationbased matched-cohort study. Ophthalmology . 2013;120: 1559-64.

85. Alvarez-Sala R, García IT, García F, Moriche J, Prados C, Díaz $\mathrm{S}$, et al. Nasal CPAP during wakefulness increases intraocular pressure in glaucoma. Monaldi Arch Chest Dis. 1994;49:394-5.

86. Kiekens S, Veva De G, Coeckelbergh T, Tassignon MJ, van de Heyning P, Wilfried De B, et al. Continuous positive airway pressure therapy is associated with an increase in intraocular pressure in obstructive sleep apnea. Invest Ophthalmol Vis Sci. 2008;49:934-40.

87. Cohen Y, Ben-Mair E, Rosenzweig E, Shechter-Amir D, Solomon AS. The effect of nocturnal CPAP therapy on the intraocular pressure of patients with sleep apnea syndrome. Graefes Arch Clin Exp Ophthalmol. 2015;253:2263-71.

88. Ulusoy S, Erden M, Dinc ME, Yavuz N, Caglar E, Dalgic A, Erdogan C. Effects of use of a continuous positive airway pressure device on glaucoma. Med Sci Monit. 2015;21:3415-9.

89. McNab AA. Floppy eyelid syndrome and obstructive sleep apnea. Ophthal Plast Reconstr Surg. 1997;13:98-114.

90. McNab AA. The eye and sleep apnea. Sleep Med Rev. 2007;11:269-76.

91. Ezra DG, Beaconsfield M, Sira M, Bunce C, Wormald R, Collin R. The associations of floppy eyelid syndrome: a case control study. Ophthalmology. 2010;117:831-8.

92. Fowler AM, Dutton JJ. Floppy eyelid syndrome as a subset of lax eyelid conditions: relationships and clinical relevance (an ASOPRS thesis). Ophthal Plast Reconstr Surg. 2010;26:195-204.

93. Muniesa MJ, Huerva V, Sánchez-de-la-Torre M, Martínez M, Jurjo C, Barbé F. The relationship between floppy eyelid syndrome and obstructive sleep apnoea. $\mathrm{Br} \mathrm{J}$ Ophthalmol. 2013;97:1387-90.

94. Muniesa M, Sánchez-de-la-Torre M, Huerva V, Lumbierres M, Barbé F. Floppy eyelid syndrome as an indicator of the presence of glaucoma in patients with obstructive sleep apnea. J Glaucoma. 2014;23:e81-5.

95. Fox TP, Schwartz JA, Chang AC, Parvin-Nejad FP, Yim CK, Feinsilver SH, et al. Association Between Eyelid Laxity 
and Obstructive Sleep Apnea. JAMA Ophthalmol. 2017;135:1055-1061.

96. Bayır Ö, Acar M, Yüksel E, Yüceege M, Saylam G, Tatar EÇ et al. The effects of anterior palatoplasty on floppy eyelid syndrome patients with obstructive sleep apnea. Laryngoscope. 2016. https://doi.org/10.1002/lary.25905.

97. Randerath WJ, Verbraecken J, Andreas S, Bettega G, Boudewyns A, Hamans E, et al. European Respiratory Society task force on non-CPAP therapies in sleep apnoea. Non-CPAP therapies in obstructive sleep apnoea. Eur Respir J. 2011;37:1000-28.

98. Aptel F, Khayi H, Pépin JL, Tamisier R, Levy P, Romanet JP, et al. Association of nonarteritic ischemic optic neuropathy with obstructive sleep apnea syndrome. JAMA Opthalmol. 2015;133:797-804.

99. Wu Y, Zhou LM, Lou H, Cheng JW, Wei RL. The association between obstructive sleep apnea and nonarteritic anterior ischemic optic neuropathy: a systematic review and metaanalysis. Curr Eye Res. 2015;4:1-6.
100. Gencer B, Ozgurhan EB, Kara S, Tufan HA, Arikan S, Bozkurt E, et al. Obesity and obstructive sleep apnea in patients with keratoconus in a Turkish population. Cornea . 2014;33:137-40.

101. Gupta PK, Stinnett SS, Carlson AN. Prevalence of sleep apnea in patients with keratoconus. Cornea . 2012;31:595-9.

102. Netzer NC, Stoohs RA, Netzer CM, Clark K, Strohl KP. Using the Berlin Questionnaire to identify patients at risk for the sleep apnea syndrome. Ann Intern Med. 1999;131:485-91.

103. Naderan M, Rezagholizadeh F, Zolfaghari M, Rajabi MT, Kamaleddin MA. Association between the prevalence of obstructive sleep apnoea and the severity of keratoconus. Br J Ophthalmol. 2015;99:1675-9.

104. Nesmith BL, Ihnen M, Schaal S. Poor responders to bevacizumab pharmacotherapy in age-related macular degeneration and in diabetic macular edema demonstrate increased risk for obstructive sleep apnea. Retina . 2014;34:2423-30.

105. Schaal S, Sherman MP, Nesmith B, Barak Y. Untreated obstructive sleep apnea hinders response to bevacizumab in agerelated macular degeneration. Retina. 2016;36:791-7. 